\title{
LA-5957-MS
}

Informa! Report

UC-20

Reporting Date: April 1975 Issued: May 1975

\section{Laser-Plasma interactions in the Scylla I-C Experiment: Preliminary Analysis}

by

Thortas M. York*

Kennetio F. McKenna

-The Pennsylvania State University, University Park, PA 16802.

An Affurmative Artion/Equal Opportunity Employer 
In the interest of prompt distribution, this report was not edited by the Technical Information staff.

\footnotetext{
Printed in the United States of Amnaca. Avaleblo from National Tochnical Iniormation Sernce

U S Departmen! of Comnerce

5285 Port Royal Roud

Springtiold, VA 2215!

Pnce: Printed Copy SA.CO Microtiche \$2.25
}

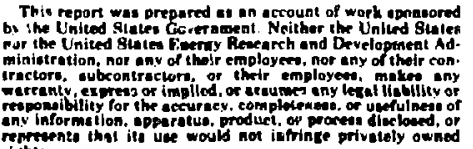

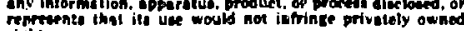


CONTENTS

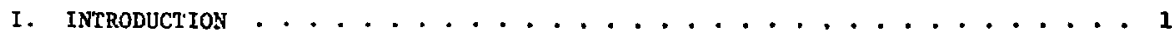

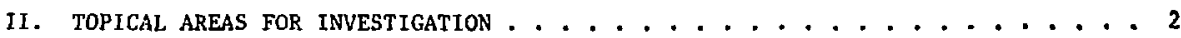

A. Laser Heating of a Static Plasma . . . . . . . . . . . . . . . 2

B. Flow or Convection Effects During Plasma Heating . . . . . . . . . . . 2

C. Flow or Convection Effecrs After Plasma heating but Before

Stablilzation in Magnetic Flelds .................. 2

III. SCYlla I-C PARAMtTERS ....................... 2

Iv. laser parameters ............................... 2

v. PROPERTIES OF THE SCYLLA I-C G-PINCH PLASMA BEFORE IASER HEATING . . . . . . . 3

A. Theta-Pinch Plasme Hodel ..................... 3

B. Implosion and Plasma Column Formation Phase . . . . . . . . . . . 3

c. Adiabat lc Compression Phase . . . . . . . . . . . . . . . . 5

vi IDEAL LASER-PLASMa INTERACTION ....................... 6

A. Inverse Bremsstrahlung Absorption Length, $\ell_{\mathrm{ab}} . \ldots . . . . . . . .6$

B. Physical Interpretation of $\ell_{a b}$................. 6

C. Inverse Bremsstrahlung Absorption with Nonlinear Absorption Coefficient . . 7

VII. PLASMA RESYONSE TO LASER ENERGY ABSORPTION . . . . . . . . . . . . . . 9

A. Electron-Electron Energy Transfer .................. 9

B. Electron-Ion Energy Equipartition ................. 10

C. Plasma Column Expansion and New Equilibrium State............ 11

D. Sequence of Plasma Events Following Laser Energy Absorption . . . . . . 12

VIIT. LASER LIGHT SCATIERING INSTABILITIES . . . . . . . . . . . . 12

A. Formulation of the Instability problem ...............13

B. Brillouin and Raman Scatcering Instability Thresholds . . . . . . . . . 14

c. Brillouln and Raman Scattering Instability length Scales........ 15

IX. LASER BEAM REFRACTION-CHANNELING AND SELF-FOCUSING . . . . . . . . . 15

A. Laser-Generated Density Gradient . . . . . . . . . . . . . . . . 16

B. Channeling and Beam Focusing with $\mathrm{dn} / \mathrm{d} r>0 \ldots \ldots 17$

X. THETA-PINCH END EFFECTS . . . . . . . . . . . . . . . . 17

XI. SUMMARY .................................. 18

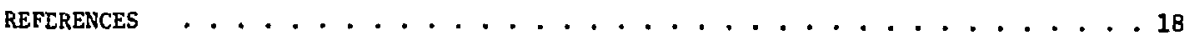

NOTICE

This report was prepared as an account of work This report was prepaed as an Government. Ne:ther sponsored by the United States Government. Neither Research and Development Administration, not any of their employecs, nor any of their contractors, their er their amployees, makes any

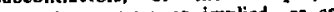
warranty, express or itmplice, or ass, mes any tegal Liability or responsibility for the accuracy, completeness or usefulness of any informstion, apparatus, product of process disclosed, or represents that its use would not infringe privately owned rights. 
LASER-PLASMA INTERACTIONS IN THE SCYLLA I-C EXPERIMENT:

\section{PREL IMINARY ANALYSIS}

by

Thomas M. York and Kenneth F. McKensa

\section{ABSTRACT}

The interaction of high power laser beams with plasmas has recently recelved considerable theoretical and experimental at tention. However, experimental determination of the laser-plasma interaction mechanisms in $\theta-p$ inch plasmas is 11mited. This work considers the interaction of a $3 \times 10^{10} \mathrm{~W} / \mathrm{cm}^{2}$ peak flux $\mathrm{CO}_{2}$ laser beam with the magnetically confined plasma generated in the Scylla $\mathrm{I}-\mathrm{C} \theta$-piuch. For the specific constraints of the $\mathrm{CO}_{2}$ laser and Scylla $I-C$, and with the 0 -pinch $f 111$ pressure as a primary variable $(100 \mathrm{mT}-1000 \mathrm{mT})$, the physical problems of plasma heating, laser light backscatter, and channeling (converging diffraction of the laser beam) are considered. Prediction of the $\theta$-pinch plasma parameters, prior to laser heating, is developed using snowplow theory.

\section{INTRODUCTION}

The concept of using high power lasers to provide an Independent source for heating a plasma to fuston temperatures in controlled thermonuclear reactors has been proposed. ${ }^{1,2}$ Efforts to proceed from concept to proof-of-concept experiments have been reported. $3,4,5$ Theoretical predictions of laser-plasma interactions have provided a basis for experimental evaluation of the physical Interaction mechanisms ${ }^{6}$ and the critical ordering of mechanisms dominant in the different interaction regimes. 7

The present work will key directly to efforts expended during the past year ac LASL, whlch served to define and Initiate a laser-plasma interaction experiment. Laser-plasma reactor concepts have been presented in lASL, report form, 8,9 and proposals for initial experiments are outlined in informal reports. ${ }^{10}$ In the LASL laser-plasma experiment, the CTR-3 Scylla I-C $\theta$-pinch will be used $n$ conjunction with a $\mathrm{CO}_{2}$ cold cathode laser, supplied by the L-1 Group of the Laser nesearch and Technology Division, to study the interaction of axfally directed long wavelength laser light $(10.6 \mu \mathrm{m})$ with the jense $\left(\mathrm{n}_{\mathrm{e}} \geqslant 10^{17} \mathrm{~cm}^{-3}\right) \partial$-pinch nlasma column. A schematic drawing of the proposed experimental plan is shown in Fig. 1. Inttially, the experimental investigation will be directed toward studying a) contalnment or afffraction of the laser beam as it vraverses the meter-long plasma column, b) heating of the plasma column by laser energy absorption, and c)

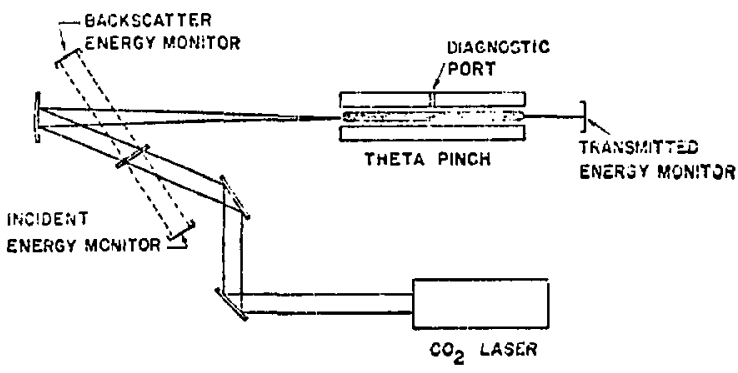

Fig. 1. Schematic of Scylla I-C laser plasma experiment. 
Instability induced anomalous baskscatter of the Incident laser 11ght. A detailed listing of possible areas of experimental investigation will be given below.

In this work, an ideal model of the Scylla I-C $\theta$-pinch plasma creation and the $\mathrm{CO}_{2}$ laser-plasma interaction, based on a well-defined $\theta$-pinch plasma geometry, is developed in order to establish the expected behavior of the laser-heated piasma. Effects such as laser light backscatter and diffraction will be considered. Finally, ef fects of higher order plasma perturbations, which are not considered in detail but do deserve further evaluation, will be discussed.

While some studies ${ }^{1,2,9}$ indicate that higher plasma temjeratures may be achieved by laser preheating followed by $\theta$-pinch compression, the present work considers only the reverse sequence, $f_{0}$., compression to a magneticall $y^{\prime}$ conf ined plasma column followed by laser heating. This approach was adopted since the immediate 1nterest in the present experiment is to study the laser-plasma interaction process, and the densities required for strong laser interaction are more readily obtalned in the compressed plastia column.

\section{TOPICAL, AREAS FOR INVESTIGATION}

The interaction of the $\mathrm{CO}_{2}$ laser beam with the Scylla I-C $\theta$-pinch plasma is analytically treated with the plasma in a right circular cylinder configuration and with the laser beam aligned along the cylinder axis. The presence or absence of convective plasma motion during and after laser heating forms a natural criterton with which to delineate the following areas of Investigation:

A. Laser lleating of a Static Plasma

1) Consequences of Inverse bremsstrahlung absorption.

1i) Thresholds for anomalous effects due to instabilities.

111) Effects of "bleaching" (variable absorption coeffictent).

1v) Species equilibration and thermal conduction effects (uniformity of heaten plasma).

v) Axial focusing or channeling due to radial density gradients.

vi) Effects of axial density gradients in the plasma column.

B. Flow or Convection Effects During Plasma Heating

i) Thresholos for local instabilities inducting convective instabllities.

ii) Radiation induced convection.

i1i) Characteristic flow times in comparison with thermal equfltbration times.

iv) ieneration of macroscopic fluld turbulence by microscupic instabilities.

c. Flow or Convection Effects After Plasma Heating but Before Stabilization in Magnetic Flelds

i) Flow and loss efiects from ends of theta pinch.

i1) Heated plasma and magnetic field interaction -- area waves.

iii) Local surface heating, blow off.

\section{SCYLLA I-C PARAMETERS}

The gaometry, energy storage capabilitles, and electrical Lischarge characteristics of the Scylla I-C $\&$ pinch have resulted from optimization studies intended to produce a dense plasma that will be compatible with the $\mathrm{CO}_{2}$ laser system performance. The machine parameters, for operation at $40 \mathrm{kV}$ mainbank voltage, are given in Table $I$.

IV. LASER PARAMETERS ${ }^{10,11}$

$\Lambda$ modification of the A-3 amplifier of the LASL $\mathrm{CO}_{2}$ laser system was chosen as a satisfactory source for the 50-100 J requirement of the experiment.

The laser characteristics are presented In Table II.

The 8-cm-diameter beam will be focused onto the end of the plasma column by one of two possible spherical reflecting mirrors. A mirror with radius of curvature, $R=6 \mathrm{~m}$, w1ll focus the beam to a $2-\pi m$

\section{TABLE I}

SCYLLA I-C MACHKNE PARANETERS

\section{Perameter}

Coil length

Coll bore

Discharge tube i.d.

Dank capacity

Source inductance

$1 / 4$ Cycle Time

Coll Electric ficld

Tube 1.d. Electric field

Cot1 Current

Peak Magnetic Field
Value

$$
\begin{aligned}
& \text { L. }=100 \mathrm{~cm} \\
& D=10.5 \mathrm{~cm} \\
& 2 \mathrm{~b}=3.8 \mathrm{~cm} \\
& \mathrm{C}_{\text {TOT }}-97.2 \mathrm{HF} \\
& L(S)=5.4 \mathrm{nH} \\
& \tau / 4 \cdot 2 \text { HS } \\
& E \text { (coil 1.d.) } 0.8 \mathrm{kV} / \mathrm{cm} \in 40 \mathrm{kV} \\
& \text { E(tube } i . d \text { d) } 0.27 \mathrm{kV} / \mathrm{cm} \text { \& } 40 \mathrm{kV} \\
& I_{\text {max }}=3.1 \mathrm{MA} 40 \mathrm{kV} \\
& \mathrm{B}_{0}(z / 4)-35 \mathrm{kG} / 40 \mathrm{kV}
\end{aligned}
$$


TABLE II

$\mathrm{CO}_{2}$ LASER SYSTEM PARAMETERS

\begin{tabular}{|c|c|c|}
\hline Parzmeter & & Value \\
\hline Optical aperturc & 50 & $\mathrm{~cm}^{2}$ \\
\hline Bean diancecr & & $\mathrm{cn}$ \\
\hline Laser lengeh & $: \quad 100$ & $\mathrm{~cm}$ \\
\hline Short pulse output & Be & $\pm 20 \mathrm{~J}$ in $60 \mathrm{~ns}\left(2 \times 1 \mathrm{j}^{9} \mathrm{~W}\right.$, peak $)$ \\
\hline Focusing mircor & $: R=6$ & $6 m$ for post-pinch heat (in focus) \\
\hline radius of curvature & $: \quad R=B$ & of for jaser preheat (out focus) \\
\hline Focused besm dianeter & : $\quad 2 \mathrm{~mm}$ & \\
\hline Laser power density & $: 5 \times 1$ & $10^{10} \mathrm{~h} / \mathrm{s} \mathrm{n}^{2}$ (nominal average) \\
\hline
\end{tabular}

spot at the near end of the plasma column. This mirror is intended for plasma column heating experiments. A second mirror with a radius of curvature of $8 \mathrm{~m}$ will be avallable for laser heating of uncompressed plasma. The $\mathrm{R}=3 \mathrm{~m}$ mirror would focus the beam at the far end of the plasma column. Only the behavior of the plasma under the influence of the near-end focus arrangenent will be considered here.

V. PROPERTIES OF THE SCYLLA I-C O-PINCH PLASMA BEFORE LASER HEATING

Since the details of the laser-plasma interaction are dependent upon the plasma electron density and cemperature, it is necessary to estimate these plasma parameters jver the anticipated range of $0-$ pinch fnitial-fill pressures. The model used to predict the plasma paraneters is developed below. A. Theta-Pin:h Plasma Model

Theta-pinch. implosion-phasc studieg carried out at LASL have corcentratid on the imploding plasma behavior in discharge tubes of maderate diameter (20 cri) and moderate fill pressure ( 10 mTorr). At $10-$ inTorr fill pressure, recent experiments ${ }^{12}$ have shown that during the early stage of the implosion ( $r_{\text {plasma }} \lesssim 7 \mathrm{~cm}$ in the 10-cm-:adius tube) the electron density is coincident with the magnetic piston field, a behavior iudicative of "snowplow" dynamics. However, half way through the implosion (r plasma $5 \mathrm{~cm}$ ), a density front which leads the magnetic piston field is observed, indicating "bounce" model behavior. ${ }^{13}$ In an investigation ${ }^{14}$ of the $\theta$-pinch plasma Implosion in : 10-cm-diameter discharge tube at higher fill pressures (50-200 mTorr hydrogen), separation of the electron density and magnetic piston fleld was not observed. The ion-ion mean free path in this case ${ }^{14}$ was aboti $0.025 \mathrm{~cm}$, compatible with a collision-dominated sheath with a thickness of about $1 \mathrm{~cm}$. Accordingly, at high-fill pressures ( 250 mTorr) and small discharge tube diameter 6 ( $\approx 10 \mathrm{~cm})$, it appears appropriate to consider the implosion as an event which is not characterized by a plane reflecting magnetic piston (bounce model), but rather an event which involves entrainment and continuous heating of the ions within the current sheath, i.e., a snowplow model. Since the basic interactions postulated in the snowplow model have not been delineated in other available references, the detalls of the development will be presented here.

Figure 2 presents the $\theta$-pinch magnetic field waveform, $B(t)$. Specific times during the discharge, used in modeling the plasma behavior, are indicated on the figure. T/4 defines the time of peak magnetic field, $B_{0}$, when the discharge current is crowbarred allowing gradual decay from the peak field. As will be seen, the pinch time, $t_{p}$ time for sheath implosion to $r=0$ ) will occur with $t_{p} \ll \tau / 4$. Thus $B$ can be assumed to increase linearly over the time of the implosion.

B. Implosion and Plasma Column Formation Phase

Neglecting acceleration effects, the inelastic snowplow momentum balance across the fmploding current sheath can be expressed as

$$
\frac{B_{s}^{2}}{8 \pi}=m_{i} n_{0} v_{s}^{2},
$$

where $m_{i}$ is the mass of a deuterium ion, $n_{0}$ is the number density of $f 111$ atoms, and $B_{s}$ and $v_{s}$ are the

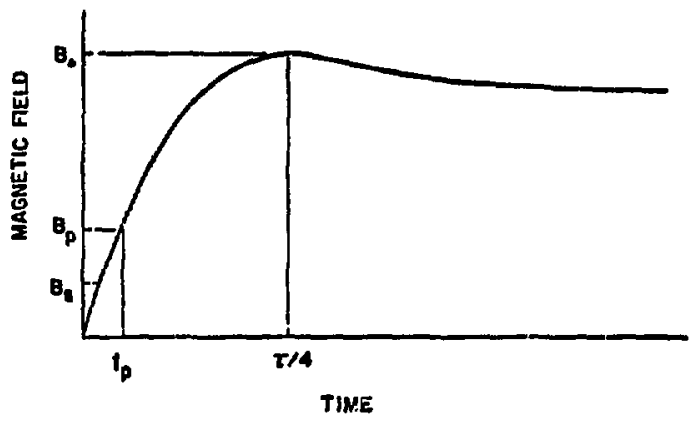

Fig. 2. (i-pinch magnecic field waveform. $B$ is the peak inagnetic fteld, $B$ the confining magnetic field at the termination of the implosion phase, and $B$ the average field over the duration of the implosion. 
average driving magnetic field and sheath veloctry, respectively. It is assumed that the sheath $1 \mathrm{~m}-$ plodes to the axis $(r=0)$ in time, $t_{p}$, with the electrons in the imploding sheath remaining cold and the ions possessing equal kinetic and thermal energies. ${ }^{15}$ As a first approximation in determining the plasua state, the fon energy acquired durIng the implosion is assumed to be converted to fon thermal energy in the plasma column. Since gas pressure in the highly compressed column will be greater than magnetic pressure at $t p$, the plasma will rapidly expand to an equilibrium position at $R_{s h}$ (plasma boundary after shock heating and expansion). The expanding plasma performs work against the confining magnecic field $B_{p}$, and a temperature $T_{p}$ and density $n_{p}$ are obtained after the expansibn to $R_{s h}$. The equilibrium energy balance at $R_{\text {sh }}$ can be approxinated as

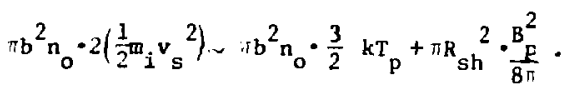

Assuming $\beta \sim 1$ ( $\beta$ is the ratio of plasma pressure to magnetic pressure), the equilibrium pressure balance at $R_{\text {sh }}$ is given by

$$
\frac{\mathrm{B}_{\mathrm{p}}^{2}}{8 \mathrm{ri}}=\mathrm{n}_{\mathrm{P}} \mathrm{kT}_{\mathrm{p}},
$$

and ccuservation of particles requires

$$
n_{0} b^{2}=n_{p} R_{s h}^{2} .
$$

Combining (4) and (5) and substituting into (3), yields,

$$
k T_{p}=\frac{2}{5} m_{i} v_{s}^{2} .
$$

Then substituting (6) Into (3) gives

$$
R_{s h}^{2}=b^{2} \frac{n_{o} k T p}{B_{p}^{2} / 8 \pi}
$$

and from equacion (5)

$$
n_{p}=n_{o}\left(\frac{b}{R_{s h}}\right)^{2} \text {. }
$$

With the speciftcation of $B_{p}$ and $v_{s}$, Eqs. (6)(8) can be solved in closed form for $T_{p}, R_{s h}$, and $n_{p} \cdot B_{p}$ can be determined by noting that during the short time of the implosion phase,

$$
B=B_{o} \sin \omega t \therefore B_{0} \omega t .
$$

Then, In this model $B_{s}=B_{o} w t_{p} / 2$ is the average value of driving magnetf fleld over the duration of the implosion. The value of the confining magnetic field $B_{p}$ at the equilibrium position $R_{s h}$ is then $B\left(t=t_{p}\right) \approx B_{o} \omega t_{p}=2 s_{s}$. With $B_{s}$ determined, the sheath velocity can be expressed from Eq. (2) as

$$
v_{s}^{2}=\frac{\left[B_{0} w t_{p} / 2\right.}{8 i m_{t} n_{0}}=\left(\frac{b}{t_{p}}\right)^{2}
$$

Using the previously noted Scylla I-C machine parameters, $B_{o}=35 \mathrm{kG}, \omega=\frac{3 j}{\tau}$ and $b=1.8 \mathrm{~cm}$ yields

$$
v_{s}=5.16 \times 10^{10} \mathrm{n}_{0}^{-1 / 4} \mathrm{~cm} / \mathrm{s}
$$

and

$$
t_{p}=3.49 \times 10^{-11} \mathrm{n}_{0}^{1 / 4} \mathrm{~s} \text {. }
$$

This analytical formulation can be compared with the experimentally determined pinch times of the piston sheath obtained In the Scylla I-B Opinch. ${ }^{16}$ Both snowplow and bounce models of the implosion process predict a dependence of pinch time, ${ }_{p}$, on the initial fill density, $n_{0}$, and the initial azimuthal electric field, $E_{\theta}$, which can be expressed as $^{16}$

$$
t_{p} \alpha b n_{0}^{1 / 4} E_{\theta}^{-1 / 2}
$$

Experimental results for Scylla $1-B^{16}$ lead to the empirical ralationship (for the 10-cm-radius discharge tube)

$$
t_{p}=9.0 \times 10^{-11} \mathrm{n}_{0}^{1 / 4} \mathrm{E}_{0}^{-1 / 2} \mathrm{~s},
$$

with $E_{0}$ in $\mathrm{kV} / \mathrm{cm}$. For the smaller radius of scylla $I-C(1.8 \mathrm{~cm})$, the pinch time, with $E_{0}=0.27 \mathrm{kV} / \mathrm{cm}$, is predicted to be

$$
t_{p}=3.2 \times 10^{-11} n_{\mathrm{o}}^{1 / 4} \mathrm{~s},
$$

within $10 \%$ of the analytical result obtalned above

[Eq. (12)].

The above model for the plasma implosion, column formation and expansion to the equilibrium posttion assumed for conventence that the electron population remalned at its initlal prefonization temperature $\sim 2 \mathrm{eV}$. Iu the plasma column, the higher energy lons will losi energy to the cold electrons as 
a result of ion-election collisions. The time for the ion energy to decrease by a factor of $1 / 0(37 \%)$, thus increasing the electron energy, is given for a deuterium plasma by ${ }^{17}$

$$
\tau_{i e}=\frac{6.3 \times 10^{8} T_{e} e^{3 / 2}}{n_{e} \ln A} \mathrm{~s} \text {, }
$$

where $T_{e}$ is in eV and $n_{e}$ in $\mathrm{cm}^{-3}$. For $T_{e} \sim 2 \mathrm{eV}$ and $\ln \Lambda \sim 6$ energy equilibration times between the Ion and electron populations are only a few nanoseconds over the entire range of inftial $f 11 i$ pressures considered (100-1000 mTorr). Accrordingly, the ion and electron temperatures rapidly equalize so that $\mathrm{T}_{\text {ep }}=\mathrm{T}_{\text {ip }}$.

With fill pressure as the varied parameter, the plasma properties following shock heating and expansion to magnetic pressure equilibrium at $B_{p}$ are given in Table III. $R_{s h}$ has constant value of b/ $\sqrt{10}=0.57 \mathrm{~cm}$ and $n_{p}=n_{e p}=n_{i p}$.

C. Adiabatic Compressior. Phase

Following the plasma implosion and expansion to an equilibrium radius $\mathrm{R}_{\text {sh }}$ with confining magnetic fields of strength $B_{P}$, the plasma is adiabatically compressed by the magnetic field increasing from $B_{F}$ at $t=t_{p}$ to $B_{o}$ at $t=\tau / 4$. The condltions at the end of the compression will be denoted by the subscript $f$. For equilibrated electrons and ions the plasma properties after compression are given by $^{18}$

$$
\begin{aligned}
& R_{i}=k_{s h}\left(\frac{B_{p}}{B_{o}}\right)^{1 / \gamma}, \\
& T_{f}=T_{p}\left(\frac{R_{s h}}{R_{f}}\right)^{2(\gamma-1)}, \\
& n_{f}=n_{o}\left(\frac{b}{R_{f}}\right)^{2},
\end{aligned}
$$

where $r=5 / 3$ for the collision dominated plasma,

\begin{tabular}{|c|c|c|c|c|}
\hline Po, wtort & $3,1.3 / v_{s}, n$ & $B_{s} \cdot B_{p} / 2,16$ & $\pi_{p^{\prime}} \mathrm{cm}^{-3}$ & $T_{p}+T_{e p} \cdot T_{\text {ip }}$ eV \\
\hline 2 & 310 & 1.4 & $7 \times 20^{26}$ & 27 \\
\hline 300 & 47 & ..e & $3.5 \times 10^{7}$ & 12 \\
\hline 1000 & 568 & 3.0 & $7 \times 10^{27}$ & 9 \\
\hline
\end{tabular}
$T_{f}=T_{e f}+T_{1 f}$ and $n_{f}=n_{e f}=n_{1 f}$.

TALLE III

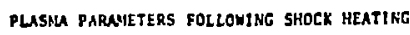

TABLE IV

PLASMA COLUMN PARAMETERJ AT MAXINUM COMPRESSION

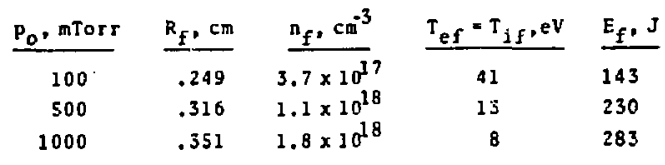

The energy resident in the plasma column of length $L$ at the termination of the adiabatic compression phase can be expressed as

$$
E_{f}=\left(\frac{3}{2} n_{f} k T\right)\left(\pi R_{f}^{2}\right) L
$$

Assuming pressure balance $(\beta \approx 1)$,

$$
E_{f}=2.3 \times 10^{3} R_{f}^{2} \mathrm{~J}
$$

for the Scylla I-C operating parameters.

With $f 111$ pressure as the varled parameter, the predicted (final) conditions of the plasma at the termination of the snowplow-adiabatic-compression processes, determined from Eqs. (17)-(21) using the values in Table III, are given In Table IV and presented graphically in Fig. 3.

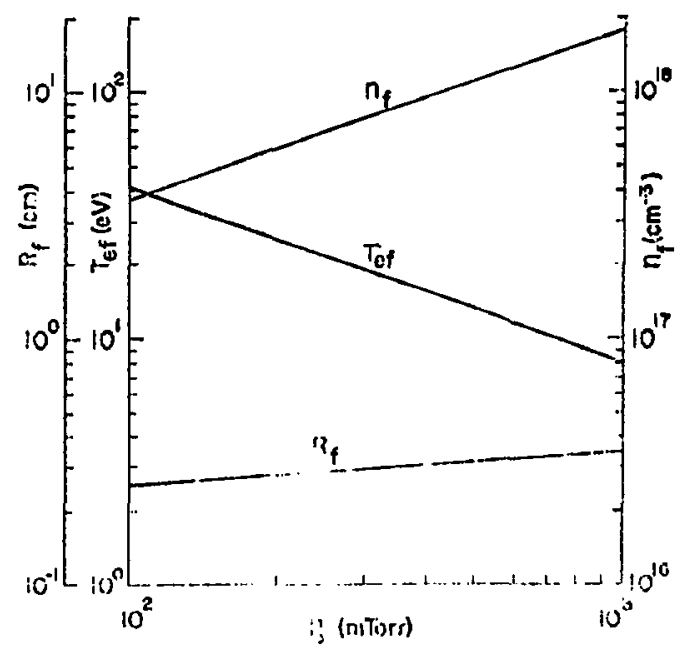

Fig. 3. Plasma column parameters at the termination of the snowplow-adiabatic-compression process as a function of inltial $\theta$-pinch fill pressure. 
The possibility of signiffcant radiant energy loss on the time scale of the pinch and adiabatic compression events must be cousidered. Assuming free-free transitions of electrons (continium radiation) to be the dominant radiant energy loss mechanism, the energy radiated per unit volume per unit time can te expressed as 17

$$
E_{R}=g\left(\frac{2 \pi k T e f}{3 m_{e}}\right)^{1 . / 2} \frac{2^{5} \pi e^{6}}{3 h m_{e} c^{3}} z^{2} n_{f}^{2}
$$

or

$$
E_{R}=1.7 \times 10^{-32} \mathrm{n}_{\mathrm{f}}{ }^{2} \mathrm{~T}_{\mathrm{ef}}^{1 / 2} \mathrm{~W} / \mathrm{cm}^{3}
$$

in the present case, with $\mathrm{n}_{f}$ in $\mathrm{cm}^{-3}$ and $\mathrm{I}_{\mathrm{ef}}$ in $\mathrm{eV}$. The greatest energy lass is found to occur at 1.000 mTorr pressure where the loss rate is $10 \mathrm{~J} / \mathrm{Hs}$ or about $2 \%$ of the total plasma energy per ps. At 100 mTorr fill, the plasma radiates about $0.2 \%$ of its energy per us. Such loss rates are sufficiently small over the time scale of the laser-plasma interaction to be neglected.

\section{IDEAL LASER-PLASMA INTERACTION}

This work will first consider the response of the plasma under the influence of the expected dom 1nant laser absorption mechanism, inverse bremsstrahlung, ignoring problems of laser light backscatter, and possible diffraction of the laser bean out of the plasma column. Thus, the results oi such an analysis will provide an 1ndication of the maximum perturbing eflect of the laset heating. This information is crucial in the evaluation of possible diagnostic techniques and the 1dentification of optimum $\theta$-pinch operating conditions. Following this analysis, each of the effects (backscatter, etc.) which serve to reduce the local energy flux, and thus the heating effect, w111 then be evaluated. A. Inverse Brensstrahlung Absorption Length, $\ell$ ab

In a fully Lonized plasma, the energy of the incident laser light is absorbed through the process of Inverse bremsstrahlung by which the electrons are accelerated in the electric fields of the focused light. The plasma ions are heated as a result of subsequent electron-ion collistons. The Inverse brrmsstrahlung absorption coefficient, $K$, has been presented by .Johnston and Dawson ${ }^{19}$ and clarifled by Kristiansen. 20 The absorption length, $\ell_{a b}$, can be expressed, in terms of $K$, as

$$
\begin{gathered}
\frac{1}{K}=l_{a b}=1.15 \times 10^{29} \frac{\left(\mathrm{kT} \mathrm{ef}^{3 / 2}\right.}{\lambda^{2} \mathrm{Zn}_{\mathrm{f}}{ }^{2} \mathrm{ln} \Lambda} \\
\cdot\left(1-\frac{\lambda^{2}}{\lambda_{\mathrm{p}}^{2}}\right)^{1 / 2} .
\end{gathered}
$$

Here $\lambda$ is the laser light wavelength, $\lambda_{p}$ the wavelength of radiation at the plasma frequency, 2 , the electronic charge rumber and $\Lambda: * v_{\mathrm{T}} / \omega \mathrm{P}_{\min }$ $\left(v_{T}=\left(\frac{k T_{e f}}{n_{f}}\right)^{1 / 2}\right.$, w the wave frequency and $P_{\text {in } 1 n}=$ $\left.\frac{\mathrm{Ze}^{2}}{3 \mathrm{kT}}\right)$ ef For $\mathrm{z}=1$ and $\mathrm{CO}_{2}$ laser $11 \mathrm{ght}(\lambda=10.6 \mathrm{x}$ $\left.10^{-4} \mathrm{~cm}\right)$, the above reduces to

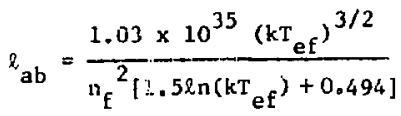

$$
\begin{aligned}
& \left(1-\frac{\mathrm{n} e f}{1.0^{19}}\right)^{1 / 2} \mathrm{~cm}
\end{aligned}
$$

for $\mathrm{n}_{\mathrm{f}}$ in $\mathrm{cm}^{-3}$ and $\mathrm{kT}$ ef in $\mathrm{eV}$.

$$
\text { Substituting the values of the plasma column }
$$

electron temperature, $T_{e f}$, and density, $n_{f}$, derived for the snowplow-adlabatic-compression model (Table IV) Into equation (25), results in the absorption lengths presented in Table $V$.

B. Physical Interpretation of $\ell_{a b}$

The physical problem under consideration is the attenuation of a laser beam, with a total incident flux density I $\left(W / \mathrm{cm}^{2}\right)$, upon passing through the plasma column where it loses an increment of flux density, KI•ds, upon traversing a distance ds.

\section{TABLE V}

LASER ABSORPTION LENGTH

$\begin{array}{llll}P_{\mathrm{o}, \mathrm{mT}} & \underline{100} & \underline{500} & \underline{1000} \\ { }_{\mathrm{o}}^{\mathrm{ab}, \mathrm{cm}} & 33 & 0.8 & 0.2\end{array}$


Ideally, neglecting scattering and emission, the distance rate of change of the incident flux density is given by,

$$
\frac{d I}{d s}=-K I .
$$

For the case with the beam entering at the plasmavacuum boundary, $S=0$, the solution of the above equation takes the form

$$
I(s)=I(0) e^{-\tau(s)} \text { where } \tau(s)=\int_{0}^{s} k \cdot d s .
$$

This functional form represents an exponential decay of the flux density along the beam path. At one absorption length the beam flux density is reduced to $1 / \mathrm{e}$ of its initial value. For constant absorption coefflcient, $K$, the above formulation allows interpretation of the absorption lengths presented in Table $v$. For a plasma with an absorption length, 'ab' greater than the plasma extent, one could expect an alnost linear decrease in absorpm tion (and thus heating) to occur along the plasma column. For an absorption length smaller than the length of the plasma, beam energy would still te deposited at positions larger than the absorption length, but with significantly reduced intensity. This simple exponential reduction in flux density can be altered by a variation in the absorpticn coeffilient, $k$, along the column due to the local plasma heating. Since $K \sim T_{\mathrm{e}}^{-3 / 2}$, local laser heating of the electron plasma reduces the absorption coefficlent (increasing $\&_{a b}$ ), thus allowing the laser beam to penetrate further Into the plasma. This nonlinear absorption process is referred to as bleaching.

C. Inverse Bremsstrahlung Absorption with Nonlinear Absozption Coefficlent

Laser-plasma interactions dominated by nonlinear inverse iremsstrahlung absorption (IBA) have been given a rather general treatment by Steinhauer and Atlstrom. 21,22 However, the strength of the physical arguments in the present case are best delineated in the work by Schappert, ${ }^{23}$ which w11l be followed here. This analysis ${ }^{23}$ assumes constant electron density withjn the interaction region with no electron-ion energy transfer and no electron thermal conduction to the sucrounding plasma over the time scale of the laser pulse. The laser beam is presumed to remain collimated at its inttial incident diameter ( 2 am in the present case) heating a cylindrical central core of the plasma column.

Nonlinear abcorption is included in the analysis through the introduction of a variable inverse bremsstrahlung coefficient which, neglecting density variations, can be written as

$$
\widetilde{K}=k\left(\frac{T_{\text {ef }}}{T_{e}}\right)^{3 / 2} \mathrm{~cm}^{-1},
$$

$\mathrm{K}$ is the Ideal IBA coefflcient defined by Eq. (24), $T_{\text {ef }}$ is the initial plasma column electron temperature (prior to the laser heating) and $T_{e}$ is the local electron temperature which varies over the duration of the laser pulse. Substicuting $\mathbb{R}$ into the time dependent radiative transfer equation and integratfing over the laser pulse length, the exact solution for the laser energy absorbed at a given axial position, $f_{i}(X)$, can be written as, ${ }^{23}$

$$
\begin{aligned}
& \mid \frac{1}{3}(.1+Q)^{3 / 5}+(1+Q)^{1 / 5} \\
& +\frac{1}{2} \ln \left[\frac{(1+Q)^{1 / 5}-1}{(1+Q)^{1 / 5}+1}\right]||_{Q(0)}^{Q(X)}=-\frac{1}{2} \mathrm{KX}
\end{aligned}
$$

$Q(x)$ and $Q(0)$ are the limits of integration. $Q(X)$ is a dimensionless parameter expressed in terms of the plasma state prior to laser heating,

$$
\eta(x)=\frac{5}{3} \frac{k E(X)}{n_{f} k T \text { ef }} .
$$

$Q(o)$ can be considered as the ratio of the Incident laser energy per unit area, $E(0)$, to the orlginal plasma thermal energy is one absorption length. Eq. (29) can be reduced to

$$
\frac{E(X)}{E(0)}= \begin{cases}e^{-K X} & \text { for } Q(0)<i \\ 1-\frac{5}{3} \frac{K X}{Q(0)^{3 / 5}} & \text { for } Q(0) \gg\left(\frac{3}{5} K X\right)^{5 / 3}\end{cases}
$$

For low energy absorption (absorptio: length > plasma extent), the constant absorption coefficient solution with exponential beam energy decay is obtained [see Eq. (27) and (31a)]. The nonexponential energy absorption, Eq. ( $31 b$ ), is indicative of. bleaching along the column. 


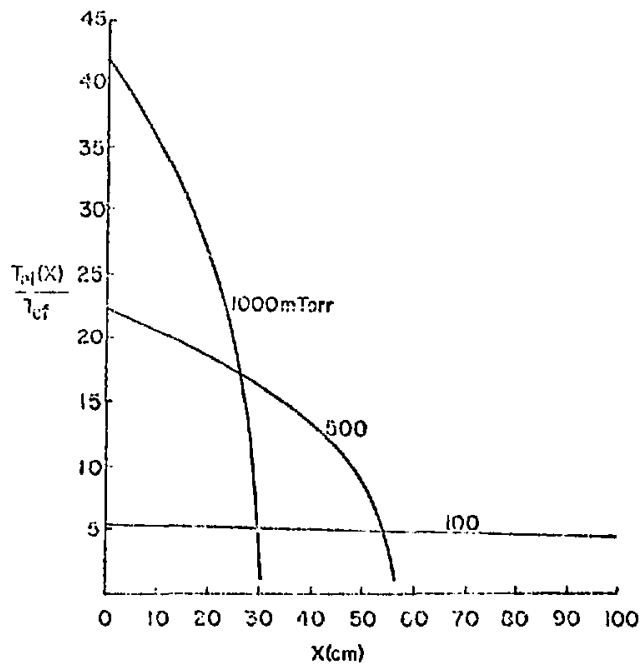

Fig. 4. Electron temperature proflies for nonlinear inverse brensstrahlung absorption coefficient. The curves represent the maximum temperature ratios in the absence of all loss mechanistus.

Integrating the electron energy conservation equation over the laser beam pulse width and applying Eqs. (31a) and (31b), the laser-1nduced electron temperature, $T_{e l}(X)$, along the 2-mm-diameter heated plasma column core can be solved for as 2.1

$$
\begin{aligned}
& \frac{T_{e h}(X)}{T_{\text {ef }}}=\left|1+Q(0) e^{-k x}\right|^{2 / 5} ; Q(0)<1 \\
& \frac{T_{e \ell}(x)}{T_{\text {ef }}}=\left|1+Q(0)-\frac{5}{3} Q(0){ }^{2 / 5} \mathrm{kX}\right|^{2 / 5} \\
& ; Q(0) \gg\left(\frac{3}{5} K x\right)^{5 / 3} .
\end{aligned}
$$

The electron temperature profiles, for various $f i l l$ pressures, are presented in Fig. 4.

For the high fill pressure cases the beam energy will be completely absorbed before reaching the far end of the plasma column, $x=100 \mathrm{~cm}$. The limiting axial station, $x_{l}$, where $E\left(x_{l}\right)=0$ is given

$$
x_{\ell}=\frac{3}{5} \frac{Q(0)^{3 / 5}}{K} ; Q(0) \gg\left(\frac{3}{5} \mathrm{kx}\right)^{5 / 3}
$$

Values of $X_{\ell}$, the initial electron temperature before heating, $T_{e f}$, and the electron temperatures after laser heating, $\mathrm{T}_{\mathrm{e} \ell}(\mathrm{x})$, for $\mathrm{x}=0$ and $\mathrm{x}=\mathrm{x}_{\ell}$ are given in Table VI as a function of $f 111$ pressure. When $x_{\ell}>100 \mathrm{~cm}$ (the plasasa column length), $\mathrm{T}_{\mathrm{e} \ell}\left(\mathrm{x}_{\ell}\right)$ is calculated at $X_{\ell}=100 \mathrm{~cm}$.

A comparison of the laser absorption lerifth, $\ell_{a b}$, obtained for constant $k$ and the length, $\tilde{l}_{a b}$ derived for the variable absorption coefficien,$\widetilde{k}$, is presented in Fig. 5. As for $\ell_{a b}$, the length $\tilde{l}_{a b}$ is defined as the axial position at which the lasex beam energy is attenuated to $1 / e$ of its initial value, 1.e., $E\left(\tilde{l}_{a b}\right)=E(0) / e$. As can be seet from Fig, 5, nonlinear absorption efgnificantly fncreases the laser beam penetration distance, the divergence between $\ell_{a b}$ and $\tilde{l}_{a b}$ increasing with fill pressure. The absorption lengths $\ell_{a b}$ and $\tilde{l}_{a b}$ actually represent two limiting cases. In the former, electron heating is neglected so that $\ell_{a b}$ is the smallest possible absorption length obtainable for a given set of initial plasma conditions. In the latter case, thermal heat conduction is neglected so that $\tilde{l}_{a b}$ is the maximun obtainable absorption length. As will be discussed below, the characteristic time for radial heat diffusion is less than the duration of the laser pulse. Accordingly, the rapid transfer of

\begin{tabular}{|c|c|c|c|c|c|c|}
\hline $\mathrm{P}_{\mathrm{o}}, \operatorname{mrcr}$ & $Q(0)$ & $\mathrm{T}$ ef, eV & $x_{1}, \mathrm{~cm}$ & $\mathrm{P}_{\mathrm{ab}} \mathrm{cm}$ & $\mathrm{T}_{\mathrm{e}^{f}}(0), \mathrm{e}^{\mathrm{V}}$ & $\mathrm{T}_{\mathrm{el}}(\mathrm{x}=100), \mathrm{eV}$ \\
\hline 100 & 66.3 & 41 & 232 & 33 & 221 & 178 \\
\hline 500 & $2.34 \times 10^{3}$ & 13 & 55 & 0.8 & 298 & 13 \\
\hline 1,000 & $1.14 \times 10^{13}$ & 8.3 & 29 & 0.2 & 348 & 8.3 \\
\hline
\end{tabular}
energy from the central core of heated plasma to the

TABLE VI

PLASM PARMMETER FOLLONING LASLR HEATING 


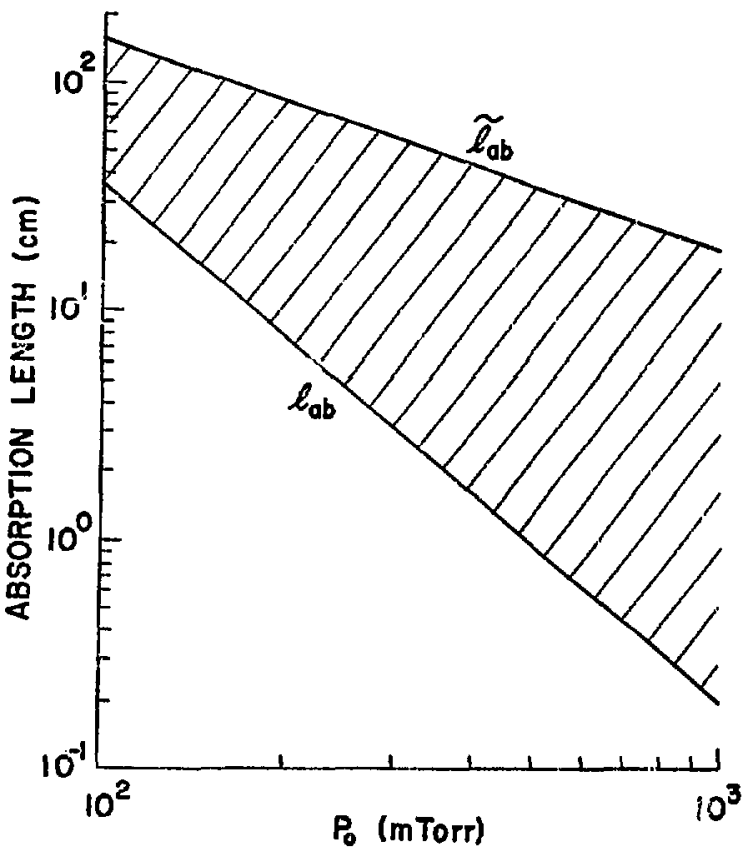

Fig. 5. Compression of laser absorption length, $q a b$, for constant $k$, and absorption length, $\widetilde{\&}_{a b}$, for variable absorption coefficlent $\widetilde{K}$.

surrounding plasma will decrease the indicated absorption length, $\tilde{\imath}_{a b}$, rogether with the electron temperature, $T_{e l}(X)$ (Fig. 4). The experimentally observed laser absorption length can cherefore be expected to fall within the crosshatched region showi in Fig. 5, being greater than $l_{a b}$ due to nonlinear absorption, but less than $\tilde{l}_{a b}$ as a result of radial heat diffusion.

\section{PLASM RESPONSE TO LASER ENERGY ABSORPTION}

in the preceding section, ideal electron heating in the 2-inm-diameter cylinder of plasma exposed to the laser beam (beam $\mathrm{d} I \mathrm{am} \approx 2$ mm) was anajyzed. The laser induced particle interactions within this hot plasma core, the transfer of energy to the surrounding plasma, and the dynamic response of the entire plasma column will now be analyzed.

\section{A. Electron-Electron Energy Transfer}

As previously discussed, the absorbed laser energy directly heats the electrons through the 11.verse bremsstrahlung mechanism. The $t i n e, t_{e e}$, for the heated electrons to attain a local Maxwellian energy distribution can be expressed as

$$
c_{\text {ee }}=\frac{3.3 \times 10^{5} \mathrm{~T}_{\mathrm{e} \ell}(\mathrm{x})^{3 / 2}}{\mathrm{n}^{\ln A}} \mathrm{~s},
$$

where $T_{e}$, is in $\mathrm{eV}$ and $\mathrm{n}_{\mathrm{e}}$ in $\mathrm{cm}^{-3}$. Using the electron temperatures at the hot end of the plasma colum, $T_{e l}(0)$ (Table $\left.V I\right), \ln \Lambda \approx 10$, and $n_{e}=n_{f}$, the calculated equilibration time for the electron population $t_{e e} \approx 1$ ns over the entire range of initial fill pressures. Thus, the electrons will maintain a Maxwellian distribution even during the duration of the laser pulse ( $50 \mathrm{~ns}$ ).

Neglecting, momentarily, local heating of the lons in the plasma core, the primary process indicing electron teraperature equilization of the not core with the remainder of the plasma column is thermal conduction. Heat conduction basically results from electron thermal transport; since the velocity of electrons greatly exceeds that of the lons, due to the mass dfference, and the plasma column is assumed to be magnetic-field free, only the electrons need be considered carriers of thermal energy. Neglecting density variations, the electron temperature equalization time is given by the time constant of the lowest order mode of heat conduction. The appropriate diffusion equation is

$$
c_{v} \frac{\partial T}{\partial t}=n \nabla^{2} T
$$

where $C_{v}$ is the plasma specific heat, $C_{v}=$ $\frac{3}{2}\left(n_{\text {ef }}+n_{1 f}\right) k$, and $n$ is the electron thermal conductivity. The characteristic thermal diffusion time can be expressed as

$$
t_{t h}=\frac{C_{v}}{n} L^{2}=\frac{L^{2}}{D},
$$

where $L$ is the characteristic length. With the electron thermal conductivity from spitzer, ${ }^{17}$ the thermal diffusivity, in the absence of internal magnetic fielos, can be written as

$$
0=\frac{6.3 \times 10^{20}}{n_{e} \ln \Lambda} T_{e l}(x)^{5 / 2} \mathrm{~cm}^{2} / \mathrm{s} .
$$

For local radial heat diffusion, $L^{2}=\left(R_{f}-R_{c}\right)^{2}$ where $R_{c}$ is the radius of the hot central core, $R_{c}=0.1 \mathrm{~cm}$, and $R_{f}$ is the plasma column boundary given in lable IV. Taking $T_{e l}(x)=T_{e \ell}(0)$, $\ell_{n} A \approx 10$, and $n_{e}=n_{f}$, the radial diffusion time $t_{t h}(R) \leqslant 1.0 \mathrm{~ns}$ in all f 111 pressure cases. Accordingly, the input laser energy is transferred locally, 
during the time of the laser pulse, to the entire plasma column electron population at a Biven axial position.

The electron temperature equilization process will have the effect of lowering the laser induced electron temperature $T_{e f}$ uniformly across the plasma column at a given axial station. The resulting temperatuxe of the electron plasma, $T_{e}^{\prime}(X)$, is determined fron a local energy balance which can be expressed as,

$$
\begin{aligned}
& \frac{3}{2} n_{f} k T_{e l}(X) \pi R_{c}^{2}+\frac{3}{2} n_{f} k T T_{e f} \pi\left(R_{E}{ }^{2}-R_{c}^{2}\right) \\
& =\frac{3}{2} n_{f} k T_{e}^{\prime}(X) \pi R_{f}^{2},
\end{aligned}
$$

where $r_{e f}, n_{f}$ and $n_{f}$ are given in Table IV. The above equation assumes that the electron density remains constant over the nanosecond time scale of the energy transfer process. The energy balance equation can be reduced to

$$
T_{e}^{\prime}(x)=T_{e \bar{T}}+\left[T_{e \ell}(x)-T_{e f}\right] \frac{R_{c}^{2}}{R_{E}{ }^{2}} .
$$

Substituting values from rable IV and VI, the resultIng electron temperatures at $x=0$ and $x=x_{\ell}$ are given in Table VII, together with the radial thermal diffusion times evaluated at $T_{e l}(0)$.

Also presented in this cable is the time for axial electron temperature equalization, $t_{t h}(z)=$ $x_{Q}{ }^{2} / D$ where $x_{Q} \leq 100 \mathrm{~cm}$ (plasma column length $=100$ $\mathrm{cm})$, calculated at $\mathrm{T}_{\mathrm{e}}=\mathrm{T}_{\mathrm{el}}(0)$. It should be noted $t_{t h}(z)$ is several orders of magnitude greater than $t_{c h}\left(R_{i}\right)$ in all cases. The electron distribution at the two extreme ends of the plasma column are effectively thermally insulated, and axial temperature equilization along the length of the plasma would not be expected to occur over the time scale of the experiment $i \gtrsim 1 \mu s)$.
TABLE VIII

ELECTRON-ION EQUIPATTITION TIME

\begin{tabular}{rrr}
$\mathrm{p}_{\mathrm{o}}$, mTorr & $\frac{\mathrm{T}_{\mathrm{e}}^{\prime}(0), \mathrm{eV}}{70}$ & $\frac{\mathrm{teq}_{\mathrm{eq}}(0), \mathrm{ns}}{100}$ \\
\cline { 2 - 2 } & 42 & 16 \\
1000 & 35 & 6
\end{tabular}

\section{B. Electron-Ion Energy Equipartition}

The electrons are heated directly by the inverse bremsstrahlung process and rapidly share their energy with the electrons in the local surrounding plasma. Ion heating results from subsequent electron-ion energy transfer collisions via the Coulomb interaction. The equipartition of energy between these two specles 1.s governed by the equatiou,

$$
\frac{d T}{d t}=\frac{T_{e}^{\prime}-T_{i f}}{t_{e q}},
$$

where $t_{e q}$ is Spitzer's $s^{17}$ equipartition time,

$$
t_{e q}=\frac{6.3 \times 10^{8} \mathrm{~T}_{\mathrm{e}}^{\prime}(\mathrm{X})^{3 / 2}}{\ddots_{\mathrm{g}} \mathrm{n} \Lambda} \mathrm{s} .
$$

Values for $t_{e q}$ evaluated at $T_{e}^{\prime}(0)$ and $n_{e}=n_{f}$ are given in Table VIII.

The electron-ion ellergy equipartition times are much larger than the radial electron thermal diffusion tines, $t_{t h}(R)$. Thus, the ton temperature lags the electron temperature on the time scale of the laser heating pulse. However, on the time scale of the experiment $\left(\gtrsim_{1} \mu s\right)$ electron-ion equilibiation is rapld enough (a few hundred $n s$ ) to affect plasma properties.

In the above calculations, it has been assumed that the plasma column does not expand before electron-ion thermalization. An estimate of the time

\begin{tabular}{|c|c|c|c|c|c|}
\hline $\mathrm{P}_{\mathrm{o}}^{\mathrm{mTor}}$ & $\mathrm{T}_{\mathrm{ef}}, \mathrm{ev}$ & $\mathrm{T}_{\mathrm{e}}^{\prime}(0), \mathrm{eV}$ & $\mathrm{T}_{\mathrm{e}}^{\prime}\left(\mathrm{x}_{\ell}\right), \mathrm{ev}$ & $t_{t h}(R), n s$ & $\mathrm{t}_{\mathrm{th}}(\mathrm{x}), \mu \mathrm{s}$ \\
\hline 100 & 41 & 70 & 63 & 0.2 & 78 \\
\hline 500 & 13 & 42 & 13 & 0.5 & 34 \\
\hline 1000 & 8 & 36 & 8 & 0.9 & 12 \\
\hline
\end{tabular}
scale for radial expansion if the plasma column boundary as a result of hot electron pressure can

TABLE VII

ELECTRON TEMPERATURE AFTER RADIAL HEAT DIFFUSION AND DIFFUSION TIMES 
TABLE IX

PLASMA EQUIPARTITION AND EXPANSION TIMES

\begin{tabular}{ccc}
$\mathrm{p}_{\mathrm{o}}, \mathrm{mTorr}$ & $\frac{\mathrm{t} \mathrm{eq}^{, \mathrm{ns}}}{100}$ & $\Delta \mathrm{t}, \mathrm{ns}$ \\
\cline { 2 - 2 } & 16 & 10 \\
1000 & 6 & 21
\end{tabular}

be obtained by equating the change of radial kinetic energy of expranding plasma to the work dont by the electron pressure in expanding the plasma against the confining magnetic fields. When expressed per unit length, this gives the differential expression,

$$
\begin{aligned}
& d\left|\frac{1}{2} m_{1} n_{f} \pi R_{i}^{2}\left(\frac{d R(x)}{d t}\right)^{2}\right|=n_{f} k\left[T_{e}^{\prime}(x)\right. \\
& \left.+T_{i f}\right] 2 \pi R(x) d R(x)-\frac{B_{o}}{8 \pi} 2 \pi R(x) d R(x),
\end{aligned}
$$

where $m_{i}$ is the fon particle mass and $R(X)$ is the outer boundary of the plasma at a given axial station. Assuming $\mathrm{T}_{\mathrm{e}}^{\prime}(\mathrm{X})$ remalns constant (and thus overestimating the expansion velocity) the above equation can be integrated and rearranged, yielding the characteristic expansion time,

$$
\Delta t=\left\{\frac{m_{1}}{2 k} \cdot \frac{\Delta R^{2}}{\left[T_{e}(X)-T_{e f}\right]\left[\frac{R(X)^{2}}{R_{f}^{2}}-1\right]}\right\}^{1 / 2} .
$$

The only unknown variable in the above equation Is the radius of the plasma boundary, $R(x)$. If the plasma expends adiabatically, the final radius will be independent of the expansion time and thus $R(x)$ can be determined from simple conservation considerations. This analysis is discussed below, but the results for $R(X)$ will be used here. Taking $T_{e}^{\prime}(X)=$ $T_{e}^{\prime}(0)$ and $R(X)=R(0)$ (Table $X I$ ), the expansion time, $\Delta t$, and the electron-ion equipartition times, $t$ eq, are given in Table IX as a furction of initial fill pressure.

It will be noted that the above $\Delta t$ values are underestintated since $T_{e}^{\prime}(x)$ decreases during the expansion. Comparing the expansion time, $\Delta t$, with the electron-ion equipartition times, $t_{\mathrm{eq}}$, it can be observed that the assumption of fon-electron equilibration before expanstion is reasonable only at the higher fill pressures. However, since the hfgher f1ll pressure cases offer the most favorable absorption conditions for laser heating $\tilde{\hat{l}}_{a b}<100$ cm) the following analysis will maintain that energy equipartition precedes expansion.

Equipartition of energy between electrons and ions further reduces the local electron temperature to a value $\mathrm{T}_{\mathrm{e}}^{\prime \prime}(\mathrm{X})$ and Increases the fon temperature to $T_{1}^{\prime \prime}(x)$. From energy balance,

$$
\begin{aligned}
& \frac{3}{2} n_{f} k T_{e}^{\prime}(x)+\frac{3}{2} n_{f} k T_{1 f}=\frac{3}{2} n_{f} k\left[T_{e}^{\prime \prime}(x)\right. \\
& \left.+T_{i}^{\prime \prime}(x)\right]=3 n_{f} k T_{e}^{\prime \prime}(x),
\end{aligned}
$$

which reduces to

$$
T_{e}^{\prime \prime}(X)=T_{i}^{\prime \prime}(X)=\frac{1}{2}\left[T_{E}^{\prime}(X)+T_{j t}\right]
$$

where $\mathrm{T}_{\text {if }}$ is the Ion temperature prior to laser heatling (Table IV). The calculaced values of $\mathrm{T}_{\mathrm{e}}^{\prime \prime}(\mathrm{X})$ at $X=0$ and $X=K_{\ell}$ are shown in lable $X$ with the initial electron temperature $T_{\text {ef }}$.

After equilibration of electron and Ion temperatures the plasma colum will have a unfform local temperature with $\mathrm{T}_{e}^{\prime \prime}(X)=T_{i}^{\prime \prime}(X)$ and a gradient in temperature will exist between axial positions. This axtal temperature gradient will be maintained for the duration of the experiment.

\section{Plasma Column Expansion and New Equilibrium \\ State \\ The rapid increase of plasma temperature by} laser heating produces a plasma-magnetic field pressure imbalance, since $B_{0}^{2} / 8 \pi<2 n_{f} k\left[T_{i}^{\prime \prime}(X)\right]$. The plasma must subsequently expand until pressure balance is again attained. Expansion is assumed to occur after laser energy aboorption and cemperature equalization between species, and he slow on the

\begin{tabular}{|c|c|c|c|}
\hline $\mathbf{p}_{\mathrm{o}}, \mathrm{mTor} \mathbf{r}$ & $\mathrm{T}^{\prime \prime}(0), \mathrm{eV}$ & $\mathrm{T}^{\prime \prime} \mathrm{e}^{\left(\mathrm{x}_{\ell}\right), \mathrm{eV}}$ & $\mathrm{T}_{\mathrm{ef}}=\mathrm{T}_{i \mathrm{f}}, \mathrm{eV}$ \\
\hline 100 & 56 & 52 & 41 \\
\hline 500 & 28 & 15 & 13 \\
\hline 1000 & 22 & 10 & 8 \\
\hline
\end{tabular}
electron-ion equilibration time scale ( $\left.\leqslant 10^{2} \mathrm{~ns}\right)$. but fast on the time scale of external magnetic

TABLE $X$

ELECTRON TEMPERATURE AFTER ELECTKON-ION ENERGY EQUIPARTITION 
fleld variations $(\sim 1 \mu s)$. The final state of the laser heated plasma is determined from the equation of pressure (assuming $B \approx 1$ ) anc energy balance, and particle conservation:

$$
\frac{B_{0}^{2}}{8 \pi}=2 n_{e}(X) k T_{e}(x)
$$

particle conservation,

$$
n_{e}(x) \pi R^{2}(x)=n_{f} \pi_{f}^{2}
$$

energy balance,

$$
\begin{aligned}
& 3 n_{\mathrm{e}}(\mathrm{x}) k T_{\mathrm{e}}(\mathrm{X}) \pi R(X)^{2}=3 n_{\mathrm{f}} k T^{\prime \prime}(\mathrm{X}) \pi R_{\mathrm{f}}{ }^{2}- \\
& \pi\left[R(X)^{2}-{R_{f}}^{2}\right] \frac{B_{o}}{8 \pi} .
\end{aligned}
$$

Here, $T_{e}(X)=T_{f}(X), n_{e}(X)$ and $R(X)$ are the local plasma temperature, density and radius after expansion. $T_{e}^{\prime \prime}(X)=T_{i}^{\prime \prime}(X), n_{f}$ and $R_{f}$ are the local plasma temperature, density, and radius immediately prior to expansion. The above equations can be conbined and rewr 1 ten as,

$$
\begin{aligned}
& T_{e}(x)=\frac{B_{o}^{2}}{8 \pi} \frac{1}{2 k n_{e}(x)}, \\
& n_{e}(x)=n_{f}\left[\frac{R_{f}}{R(X)}\right]^{2} \text { and } \\
& R(X)^{2}=\frac{2}{5} R_{f}^{2}\left[1+\frac{3}{2} \frac{T_{e}^{\prime \prime}(x)}{T_{e F}}\right] .
\end{aligned}
$$

Values of $T_{e}(X), n_{e}(X)$ and $R(X)$ after expansion of the heated plasma column are given in Table $X I$.

\section{Sequence of Plasma Events Following Laser}

\section{Energy Absorption}

The values presented in Table $X I$ represent the final state of the plasma after laser heating,

\begin{tabular}{|c|c|c|c|c|c|}
\hline$P_{0}, \mathbf{m}$ & $T_{0}(0), \mathrm{dV}$ & $\mathrm{ne}_{\mathrm{e}}(0) \cdot \mathrm{cm}^{-3}$ & $R[0], c)$ & $I_{e}\left(x_{e}\right), e v$ & $\mathrm{n}_{e}\left(x_{e}\right) \cdot \mathrm{cm}^{-3}$ \\
\hline 100 & 49 & $3.1 \times 10^{17}$ & .274 & 48 & $3.2 \times 10^{17}$ \\
\hline 500 & 23 & $0.7 \times 10^{17}$ & .406 & 15 & $1.0 \times 10^{13}$ \\
\hline 1000 & 17 & $1.1 \times 10^{18}$ & .495 & 10 & $1.9 \times 10^{13}$ \\
\hline
\end{tabular}
thermal equilibration, and plasma expansion. The sequence of events characterizing the plasma response to input laser energy is summarized below. It should be understood that such a characTABLE $X I$

EQULLIORTLM PLASMIA PARMETERS terlzation is somewhat artificlal, since each event is interdependent.

1. Laser input energy pulse of time duration $t_{k}$ is absorbed by the electrons in the 0.2-cm-diameter central core of plasma.

1) Electrons in core thermalize with tee $t_{\ell}$, 1ncreasing the electron temperature to $T_{e \ell}(x)$.

2. Electron thermal energy diffuses radially.

1) Electrons in core thermalize with the electrons in the surrounding plasma with $t_{t h}(R) \approx$ $t$ ee, decreasing the local electron temperature to $T_{e}^{i}(X)$.

3. The electrons and fons thermally equilibrate.

1) Plasma temperature becomes radially uniform with $t_{\text {eq }} \gg t_{t h}(R)$, decreasing the electron temperature and increasing the fon temperature until $T_{e}^{\prime \prime}(X)=T_{1}^{\prime \prime}(X)$.

4. The plasma column expands unt1l pressure equilibrium is again obtained.

1) The outer boundary of the plasma expands with $\Delta t>t_{e q}$, uniformly decreasing both fon and electron temperatures to their final values, $T_{e}(X)=$ $\mathrm{T}_{1}(\mathrm{X})$.

The results presented above represent the 1 dealized changes in the $\theta$-pinch plasma that could be expected during the course of the scylla I-c laserheated plasma experiment. Specific aspects of $1 \mathrm{n}-$ terest are the axial variation of equilibrium radius, changes of electron and ton temperatures at one partfcular point, axial vartation of temperatures, and changes in electron denstiy following the laser heating, as well as the time history of these variables. The results presented above represert maximum changes in variables as the calculations have rot included anomalous backscatter effects due to instabilities and beam divergence because of radial gradients in the electron denstity. Each of these effects will now be considered.

\section{LASER LIGHT SCATTERINC INSTABIJITIES}

The irradiation of plasma with laser light of sufficlent power level can cause "laser driven instabilities" to occur which result in anomalous backscatter $^{24}$ or absorption ${ }^{25}$ of the laser 1ight. Anomalous absorption instabilities are effective for laser radiation near the plasma frequency or twice the plasma frequency. In the Scylla I-C experiment 
$\omega_{0} \ll \omega_{\text {pe }}\left(\omega_{0}\right.$ is the $\mathrm{CO}_{2}$ laser light frequency and $\omega_{\text {pe }}$ the plasma frequency) and thus anomalous absorption instabllities will not be important. However, laser light scattering instabilities, which occur in underdense plasmas, could result in the reflection of a significant fraction of the incident laser radiation. The theory ${ }^{26}$ of such scattering processes Indicates that the energy of the incident light wave is reflected by the plasma through the generation of a backward-traveling light wave and either a low frequency ion wave (stimulated Brillouin scattering Instabllity) or an electron plasma wave (stimulated Raman scattering Instability). In the laser heating of underdense magnetically confined plasmas of interest here, or laser-produced plasmas of higher density, a knowledge of the depth of laser penetration allowed by these instabilities and the amount of incident laser energy reflected (backscatter) is required.

Laser scattering by plasma instabilities is currently recelving a great deal of theoretical study. 26-31 Much work has been done on scattering instabilities in homogeneous plasmas ${ }^{26}$ and more recent studies have treated inhomogeneous plasmas. 27 Thermal self-focusing Instabliftles (stimulated Rayleigh scattering) have also been theoretically identified. 28 However, experimertal confirmation of the scattering Instability mechanisms has not yet been established. With the moderate power levels $\left(\sim 3 \times 10^{10} \mathrm{~W} / \mathrm{cm}^{2}\right)$ of the present experiment and the generally unresolved nature of the instability hierarchy, this work will concentrate upon identifying the power thresholds for excitation of instabilities and the backscatter scale lengths for Brillouin and Raman scattering instabilities, which are expected to be of primary importance. ${ }^{29}$ A. Formulation of the Instability Problem

The set of coupled wave equarions which describe the evolution of the scattering instabilities are obtained by combining the fluid equations for lons and electrons with Maxwell's equations. Nonlinear theory includes the reaction of the tackscattered light wave and electrostatic plasma waves on the incident wave. It can be shown ${ }^{30}$ that the solution of this set of equations is completely described in terms of three waves exclted by the incident laser 1ight. Two of the excited waves are electromagnetic, the backscattered wave and a forward traveling nonresonant wave. The forward scattered "Stokes" wave, not being in resonance, can generally be neglected. The remalning excited wave is electrostatic, being either an ion wave (Brillouin scattering), or an electron plasma wave (Raman scattering).

When the combined fluid and Maxwell equations are Fourier analyzed in the spatial coordinate, the temporal evolution of the instabilities, their growth rates, and excitation power levels, can be obtained. The Fourler analyzed equations describe three coupled harmonic oscillators (the incldent light wave, backscattered 11ght wave, and an electrostatic wave) whose time behavior is different, depending on the magnitude of scattering instability growth rate, $\gamma_{0}$, as compared to the frequency of the electrostatic wave, $w$. The growth rate is found to be a function of the incident laser light power level. 30 For $\gamma_{0}>\omega$, the "strong coupling" limit is obtained. In this regime the incident light wave determines the properties of the electrostatic wave, and the energy in the backscattered electromagnetic wave rapidly approaches that of the Incident light wave. It will be noted that the introduction of nonlinear effects, ${ }^{30}$ such as anomalous damping of the electrostatic wave, can significantly decrease the predicted amount of backscattered laser energy. The "weak coupling" IImit, the general category of the present experiment, results when $\gamma_{0}<w$. In this regime the incident 1ight wave does not greatly affect the frequency of the electrostatic wave. The theory developed for weak coupling will be used in the following discussion.

When the comblned fluid and Maxwell equations are Fourler analyzed in time, the spatial evolution of the laser-Induced Instabilities is obtained. From these resulting equations, the characteristic instability length scale, $L_{1}$ is determined. ${ }^{30} L_{1}$ describes the exponentiation distance of the backward scattered light wave obtained when damping effects on the electrostatic wave are neglected; 1t may also be thought of as the distance into the plasma at which total reflection of the incident laser light will occur. Computer simulations 30 indicate that the exclusion of damping effects is generally not valid. A dimensiunless parameter, $\beta$, 
which describes the damping of the electrostatic fon or electron plasma waves, is thus introduced into the problem formulation. Then the factor $B L_{1}$, which is dependent on the properties of the plasma and the incident laser power level, determines the penetration depth of the incident laser light. Strong damping of the electrostatic waves, $\beta \gg 1$, allows greater laser light penetration of the plasma than weak damping, $\beta \sim 1$. Thus for finite plasmas where the plasma length, $\ell$, is $\ll 10 B \mathrm{~L}$, no significant backscattering of the incldent light is expected. llowever, if $\ell \sim 10.3 \mathrm{~L}_{1}$, bacliscatter Instabilities will be Important. $10 \mathrm{NL}_{1}$ can be shown ${ }^{30}$ to be the penetration distance at which $50 \%$ of the incident laser light is reflected.

An additional length scale for laser light backscatter has been resently proposed by ilu. Rosenbluth, and white. ${ }^{27}$ They consider the propagation of an electromagnetic "noise pul.se" from a point far from the plasma boundary. As it propagates, the pulse grows at a rate, $Y_{0}$, with a scale length, $c / 2 \gamma_{o}$, where $c$ is the speed of light. If $10\left(\mathrm{c} / 2 \gamma_{0}\right)$ is the smallest length involved in the lasser-plasma interaction problem, then this effect dominates, and the scattering could be greatly enhanced. Although the theory dealing with the amplification and propagation of notse pulses is not well developed, and can be constdered speculative at the present $t$ ime, it is noted here for completeness.

B. Brillouin and Raman Scattering Instability Thresholds

The Brillouin and Raman instabllity thresholds, growth rates, and scale lengths are dependent on the power level of the Incident laser light and the temperature and density of the irradiated plasma. The power level dependence is written in terms of the electron velocity, $v_{0}$, induced by the electric field of the incident 11ght. For plane polarized light this velocity can be expressed as

$$
v_{0}=25 \lambda_{0} \sqrt{\mathrm{P}} \mathrm{cm} / \mathrm{s} \text {, }
$$

where $\lambda_{0}$ 1s the laser wavelength in units of microns $\left(10^{-4} \mathrm{~cm}\right)$ and $P$ is the incident power density in units of $\mathrm{W} / \mathrm{cm}^{2}$.

In the weak coupling regime, the Brillouin instab1lity ${ }^{30}$ occurs when $\omega_{0}=\omega_{s}+\sqrt{c^{2}\left(k-k_{0}\right)^{2}+\omega_{p e}{ }^{2}}$ (obtalned from balancing growth with damping); which
Implies $k \approx 2 k_{0}$, since $\omega_{s} \ll \omega_{0}$ and $\omega_{p e}{ }^{2} \ll c^{2}$. $\left(k-k_{0}\right)^{2}$. Here, $\omega_{B}=k \sqrt{T} \mathrm{~T}_{1}$ is the ion wave frequency, $k$ the wave number of the ion wave, $k_{0}$ the wave number of the incldent light of frequency $\omega_{0}$, and $\omega_{\text {pe }}$ is the plasma frequency. The power threshold is then

$$
\frac{v_{0}^{2}}{v_{e}^{2}}>16 \frac{\gamma_{p}}{\omega_{s}} \frac{\gamma_{-}}{\omega_{0}} \frac{\omega_{0}^{2}}{\omega_{p e}^{2}} \text {, }
$$

where $v_{e}=\sqrt{T_{e} / m_{e}}$ is the electron thermal veloctty, $\gamma_{-}$is the collisional damping coefficient, $\gamma_{-}=$ $\nu_{\mathrm{ei}} \omega_{\mathrm{pe}}{ }^{2 / 2} \omega_{0}$ ( $\nu_{\mathrm{el}}$ is the electron-ion collision frequency), and $\gamma_{p}$ is Landau damping rate. For a plasma where $T_{e} \approx T_{1}$, as in the present case, and $k \lambda_{D}<$ 1 ( $\lambda_{D}$ is the Debye shlelding distance), the ratio $\gamma_{p} / \omega_{s} \approx 0.43 .{ }^{32}$ The instabllity growth rate is then given by,

$$
\gamma_{0}=\frac{k}{4} \frac{v_{0} \omega_{p 1}}{\sqrt{\omega_{s} \omega_{0}}} s^{-1} \text {. }
$$

For Ramen scattering, ${ }^{30}$ the balancing of tustability growth with damping occurs when $\omega_{0}=$ $\sqrt{w_{p e}^{2}+3 k^{2} v_{e}^{2}}+\sqrt{c^{2}\left(k-k_{0}\right)^{2}+w_{p e}^{2}}$, since $3 k^{2} v_{e}^{2} \ll$ $\omega_{\text {pe }}^{2}$, then

$$
k=2 k_{0}-k_{0}\left(\frac{\omega p_{e}}{w_{0}}\right) \mathrm{cm}^{-1},
$$

where $k$ in this case is the wave number of the electron plasma wave. The threshold power at this matching condition is then

$$
\frac{v_{0}^{2}}{c^{2}}>16 \frac{\gamma_{p}^{\prime} \gamma_{-}}{\omega_{k} \omega_{0}} \frac{\omega_{k}{ }^{2} \omega_{o}\left(\omega_{o}-\omega_{k}\right)}{c^{2}{ }^{2} \omega_{p e}{ }^{2}} \text {, }
$$

where $\omega_{k}$ is the electrostatic wave frequency. With $k \lambda_{D}$ small, the Landau damping rate, $\gamma_{p}$, is replaced by $\gamma_{p}^{\prime}=\left(Y_{p}+v_{e 1}\right)$ for the electron plasma wave,

$\gamma_{-}=\left(\nu_{e i} / 2\right)\left[\omega_{p e}{ }^{2} /\left(\omega_{o}-\omega_{k}\right)^{2}\right]$ and $\omega_{k}^{2}-\omega_{p e}{ }^{2}+3 k^{2} v_{e}^{2}$.

The Instability growth rate is

$$
\gamma_{0}=-\frac{k v}{4} \frac{\omega_{p e}}{\sqrt{\omega_{k}\left(\omega_{0}-\omega_{k}\right)}} a^{-1} \text {. }
$$

From the above expressions, the threshold power levels required for excitation of the Brillouin and Raman scattering instabilities and the instability 
growth rates, can be calculated for the previously determined plasma conditions presented in Table IV. The power levels and growth rates for instabllities are given in Table XII as a function of inftial fill pressure.

The $\mathrm{CO}_{2}$ laser beam power level in the Scylla I-C experiment will be approximately $3 \times 10^{10} \mathrm{~W} / \mathrm{cm}^{2}$. At this power level, it can be seen from Table XII that the Brillouin scattering instability may be excited over the entire range of inttial fill pressures, with the possible exception of the 1000 mTorr fill case. The Raman instability would not be expected to occur at $f 111$ pressures much above 100 mTorr.

c. Brillouin and Raman Scattering Instability Length Scales

For both Brillouin and Raman instabllities the primary length scale $L_{1}$, which is derived by neglecting damping effects, can be expressed as 30

$$
L_{1}=4 \sqrt{\gamma} \frac{c}{v_{0}} \lambda_{D}\left(\frac{k}{k_{o}}\right)^{1 / 2} \mathrm{~cm} .
$$

For Brillouin scattering, $\gamma=1$ and $k \approx 2 k_{0}$. In the Raman case $\gamma=3$ and $k \lesssim 2 k_{0}$ as presented in Section VIII B.

Damping of the electrostatic wave, which is indicated by the dimensionless parameter $B$, is given for Brillouin scattering as

$$
\beta=4 \frac{r_{p}}{u_{s}} k \lambda_{D} \frac{c}{v_{0}}\left(\frac{k}{k_{0}}\right)^{1 / 2}
$$

and Raman scattering by

$$
\beta=\frac{4}{\sqrt{3}} \frac{\gamma_{p}^{0}}{\omega_{p e}} \frac{1}{k \lambda_{D}} \frac{c}{v_{0}}\left(\frac{k}{k_{o}}\right)^{1 / 2} .
$$

For the $\mathrm{CO}_{2}$ laser beam with Incident power level of $3 \times 10^{10} \mathrm{~W} / \mathrm{cm}^{2}$, the laser light penetration distance, $10 \mathrm{BL}_{1}$, at which theory predicts $50 \%$ backscatter of the incident light, is given in Table XIII for both Brillouin and Raman scattering instabilicies. The inverse bremsstrahlung absorption length, $\ell_{a b}$, and the scale length proposed to indicate amplification, $10\left(c / 2 \gamma_{0}\right)$, are also presented.

For both Brillouin and Raman scattering the absorption length, $\ell_{a b} \lesssim 10 \mathrm{BL}_{1}$. For cases where $\ell_{a b} \ll 10 \beta L_{1}$, Instability scattering theory cannot be applfed and backscatter may or may not be observed. For $l_{a b} \approx 10 \mathrm{BL}_{1}$ local plasma heating effects, which increase the required power level for instability, must be considered. In such a case, the local increase of electron temperature could shut of the instability and thus the observation of scattering is uncertain.

\section{LASER BEAM REFRACTION-CHANNELING AND SELF-} FOCUSING

In the theoretical study of laser heating of confined plasmas, it has been proposed that gradients within the plasma would refract the laser beam towards regions of lower density ${ }^{33}$ (higher index of refraction). If the incident laser light is directed along the cylindrical plasma column axis, as in the precent case, then a density mininum on axis $(\mathrm{dn} / \mathrm{dr}>0)$ should result in channeling of the beam down the column axis, and possibly beam self-focueing. Conversely, the laser beam would be expected to refract awa; from the axis, and thus out of the plasma column, if the plasma density has an on-axis maximum. Experimentally, it has been estab1 ished $^{3,34}$ that channeling of the laser beam does result when the plasma has a density minimum on

TABLE XII

INSTABILITY POWER THRESHOLDS AND GROWTH RATES

\section{Brillouin Instability}

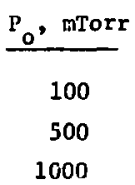

$\mathrm{P}, \mathrm{W} / \mathrm{cm}^{2} \quad \mathrm{Y}_{0}, \mathrm{~s}^{-1}$

$6.1 \times 10^{9}$

$2.4 \times 10^{10}$

$4.0 \times 10^{10}$
$2.6 \times 10^{10}$

$3.9 \times 10^{10}$

$8.5 \times 10^{10}$
Raman Instability

$\begin{array}{ll}\mathrm{P}, \mathrm{W} / \mathrm{cm}^{2} & \frac{Y_{\mathrm{o}} \mathrm{s}^{-1}}{2.1 \times 10^{10}} \\ 8.0 \times 10^{12} & 7.1 \times 10^{10} \\ 1.2 \times 10^{14} & 7.8 \times 10^{10}\end{array}$




\section{INSTABILITY LENGTH SCALES}

\section{Brillouln Scattering}

$\begin{array}{ccc}p_{0}, \text { mTorr } & \frac{10 \mathrm{~L}_{1}, \mathrm{~cm}}{10 \frac{\mathrm{c}}{2 \gamma_{\mathrm{o}}, \mathrm{cm}}} \\ \frac{39}{500} & 4.8 & 6 \\ 1000 & 1.0 & 2.5\end{array}$

axis, and for low power density laser beams $\sim 10^{7}$ $W / \mathrm{cm}^{2}$ ), refraction of the bean out of the plasma has been observed ${ }^{3,34}$ for the case of an on-axis density maximum. However, Hof $f_{\text {man }}{ }^{35}$ has found that a laser beam of suffictent power density $\left(\sim 10^{10} \mathrm{~W} / \mathrm{cm}^{2}\right)$ can create and malntain an on-axis density minimum (and chus channel) even if a density maximum is initially present on axis of the confined plasma column. It would thus appear that a laser power density "selfchanneling" threshold exists, above which the laser beam will "dr111" its own density minimum through the plasma regardless of the on-3xis density conditions. It might be expected that such a threshold would coincide with the inftiation of the "bleaching" phenomena discussed earlier. It should be noted that in Hoffman's experiment, ${ }^{5,35}$ the plasma column length was an order of magnitude smaller $(10 \mathrm{~cm})$ than the column produced in Scylla I-C. (100 cm). Accordingly, the investigation of beam channeling in the present experiment, and the possible identification of the self-channeling threshold, is of significant interest.

Considering the experinental evidence above, it appears realistic, in the present experiment, to presume that the incident $3 \times 10^{10} \mathrm{~W} / \mathrm{cm}^{2}$ laser beam wIIl sufficiently heat the plasma to create and maintain a density minimum on axis over duration of the laser pulse. With this assumption, an estimate of the laser generated density gradlent and the assuciated beam reiraction and self-focusing effects can be made.

A. Laser-Generated Density Gradient

In order for the incident laser beam to channel down the plasma column axis, a density minimum must be created during the early stages $\left(t<t_{\ell}\right)$ of
Raman Scattering

\begin{tabular}{|c|c|c|}
\hline$\ell_{a b^{\prime}} \mathrm{cm}$ & $10 \mathrm{BL}_{1}, \mathrm{~cm}$ & $\frac{c}{2 \gamma_{0}, \mathrm{~cm}}$ \\
\hline 31 & 60 & 2.5 \\
\hline 0.9 & 372 & 1.9 \\
\hline 0.2 & 1402 & 1.9 \\
\hline
\end{tabular}

laser pulse. The maximum attainable local electron temperature of the 2-mm-diameter heated plasma core at the end of the pulse duration is $T_{e l}(x)$, neglecting thermal heat conduction, electron-ion equipartition and plasma column expansion. Although electronfon temperature equilibration can be neglected for times $t<t_{\mathrm{l}}$, electron heat conduction is quite rapid $\left(t_{t h}(R) \sim 1 \mathrm{ng}\right)$ and this process w11l determine the maximum electron temperature at any given time durIng the laser heating pulse. As an order of magnitude estimate, the transient electron temperature of the heated plasma core will be assumed to approach the temperature obtained as a result of thermal heat conduction, $T_{e}^{\prime}(X)$, (Table VII).

Before laser heating, the plasma-magnetic field pressure balance can be written as,

$$
n_{f} k\left(T_{e f}+T_{1 f}\right)=\frac{B_{a}^{2}}{B \pi} .
$$

for $1 \sim 1$. During the laser heating pulse, the electzon temperature in this model is assumed to increase from $T_{\text {ef }}$ to $T_{\mathrm{e}}^{\prime}(\mathrm{X})$. Locally expanding the heated plasma to a mean density $n_{e}^{\prime}$. The resulting pressure balance between the heated core and the surrounding plasma (or equivalently, the external field) can be expressed as

$$
n_{e}^{\prime} k\left[T_{e}^{\prime}(x)+T_{1 f}\right]-\frac{B_{0}^{2}}{8 \pi} .
$$

Combining equations (61) and (62), the average density of the heated plasma is,

$$
n_{e}^{\prime}=\frac{n_{f}}{\left[\frac{T_{e}^{\prime}(x)}{T_{f}}+\frac{1}{2}\right]} .
$$


TABLE YIV

LASER INDUCED DENSITY GRADIENTS

\begin{tabular}{|c|c|c|}
\hline$P_{0}$, trTor $r$ & $\pi_{e}^{1} / \mathrm{nf}$ & $\mathrm{dn}_{\mathrm{e}} / \mathrm{dr}, \mathrm{cm}^{-4}$ \\
\hline 100 & 0.74 & $9.6 \times 10^{17}$ \\
\hline 500 & 0.47 & $5.8 \times 10^{18}$ \\
\hline 1000 & 0.36 & $1.2 \times 10^{19}$ \\
\hline
\end{tabular}

Since the laser heating is spread over the radlus of the laser beam, $R_{c}(\sim 1 \mathrm{~mm})$, an estimate of the density gradient induced by local heating can be taken as

$$
\frac{d n}{d r} \sim \frac{\Delta n}{\Delta R} \approx \frac{n_{r}-n_{e}^{\prime}}{R_{c}} .
$$

Based on the parameters of the present experiment, with $T_{e}^{\prime}(X)=T_{e}^{\prime}(0)$, the numerlcal values shown on Table XIV are determined.

\section{B. Channeling and Beam Focusing with $d n / d r>0$.}

The refraction of the laser beam within the confined plasma column can be determined from calculated light ray trajectories. The expression for the ray path, $r(X)$, at any axlal position $X$ within the plasma can be derived from the implicit ray equation ${ }^{33}$

$$
x=\left(1-\zeta_{0}\right)^{1 / 2} \int_{\Sigma_{0}}^{r} \frac{d r}{\left(\xi_{0}-\zeta\right)^{1 / 2}},
$$

where $r_{0}=r(X=0)$ defines the entry radius of a specific ray, $\zeta_{0}=\zeta\left(r_{0}\right)$ and $\zeta(r)=n_{e}(r) / n_{e c}$ is the ratio of plaum denity to the citical density (at $n_{e c}$ the laser frequency equals the plasma freguency).

Assuming a linear increase in electron density with radius over the heated plasma core, and designating the minimum dencity on axis as $n_{m}$, the density profile can be written as,

$$
\zeta(r)=\zeta_{\mathrm{m}}+(\mathrm{d} \zeta / \mathrm{dr}) \mathrm{r}, \quad \mathrm{r} \approx \mathrm{R}_{\mathrm{c}},
$$

where $\zeta_{m}=n_{m} / n_{e c}$ 1s the value of $\zeta$ on axis $(t=0)$, and $\mathrm{d} \zeta / \mathrm{dr}=\left(1 / \mathrm{n}_{\mathrm{ec}}\right) \mathrm{dn_{e }} / \mathrm{dr}$. From conservation of line density, it can be show that

$$
n_{m}=n^{\prime}-\frac{2}{3} R_{c} \frac{d n_{e}}{d r},
$$

where $n^{\prime}$ is given by Eq. (63). When the expression for the linear denoity profile, $\zeta(r)$, is substituted
Into Eq. (65) and the integration carried out, the ray trajectory equation,

$$
r(x)=r_{0}-\frac{1}{2\left(1-\zeta_{0}\right)}\left(\frac{d c}{d r}\right) x^{2},
$$

is obtained. This expression gives the radial location of any ray enterins the plasma columa at $0<r_{0}$ $\lesssim R_{c}$ as a function of axial position, $x$.

Considering the ray entering the plasma at $r_{0} \approx$ $\mathbf{R}_{\mathrm{c}}$ where $\zeta_{0} \approx \zeta\left(\mathbf{r}_{0}\right) \approx n_{\mathrm{f}} / \mathbf{n}_{\mathrm{ec}}$, the ray equation becones

$$
r(x)=R_{c}-\frac{1}{2\left(n_{e c}-n_{f}\right)}\left(\frac{d n_{e}}{d r}\right) x^{2} .
$$

For $\mathrm{CO}_{2}$ laser radiation $\mathrm{n}_{\mathrm{ec}} \approx 10^{19} \mathrm{~cm}^{-3}$, signif1cantly larger than the grestest density expected in the present experiment $\left(\approx 10^{18} \mathrm{~cm}^{-3}\right)$. Accordingly, with $d n_{e} / d r>0$ converging diffraction of the incident laser light is indicated in all cases since $r(x)<R_{c}$ for all $x>0$. Further, $E q$. (69) predicts that for sufficiently large $X$, point-focusing I $(X)$ +01 of the channeling laser beam will occur. The axial position, $e_{f p}$, at which all of the internal laser beam is focused to a point can be obtained by setting $r(X)=0$ in Eq. (69) and solving for $X$ ( = $\ell_{f_{p}}$ ). (It should be noted that total focusing of the laser beam will not occur since, in any real plasma, the density gradient $(\mathrm{dn} / \mathrm{d} x$ ) goes to zero as $r+0)$. Using the values of $\mathrm{dn}_{\mathrm{e}} / \mathrm{dr}$ given in Table XIV, It can be seen that $\ell_{\text {fp }} \leqslant 2 \mathrm{~cm}$ for all fill pressures. With $l_{t p}<l_{a b}$, In all canas, local "hot spots," beam filamentation and the necessarily Inherent nonlinearities associated with intenue heating of very small plasma volumes, might be expected to occur. Such phenomena could represent a sertous problem tor the present 100-cm-long plasma column heating experiment and for future fusion applications. These effects will be investigated in detail in the present experiment.

\section{THETA-PINCH END EFFECTS}

The results presented above neglect the effects of convective loss of plasma from the ends of the theta pinch, as well as axial plasma energy loses. Both of these effects could have a pronounced influence on the expected laser-plasma interaction through alteration of the local density and temperature profiles and related factors, wuch as the 
ordering of characteristic times. Although the plasma end loss time ( $\tau \sim \mathrm{L} / \mathrm{v}_{1} \approx 10 \mu \mathrm{s}$ at $100 \mathrm{eV}$ ) is much larger than the laser pulse time ( $50 \mathrm{~ns}$ ), the possibility of local "blow off" at the hot end of the plasma columen is highly possible in the present experiment. This effect could algnificantly alter existing theorles ${ }^{30}$ for end loss involving area wave perturbations of the magnetic confinement equilfbrium. Clearly, this problem requires investigation as it relates to the present experiment and future Eusion applications.

\section{SURMARY}

The present analysis has attempted to provide a preliminary indication of the results that can be expected in the proposed Scylla I-C laser-plasma inceraction experiment. Throughout the analysis, 1t has been assumed that the incident laser beam w11l create and malntain the approprlate on-axis density conditions required for channeling. If self-channeling is not obtained, simple modtfication of the Scylla I-C theta pinch can be carried out, which would result in the creation of favorable onaxis density conditions necessary for trapping the laser 11ght. In efther case, the basic analytical procedures used in this work can be applfed to estimate the results of the laser-plasma interaction.

Using snowplow theory as the relevant highdensity model with $B \approx 1$, Scylla I-C plasmas in the $10^{17}$ to $10^{18}$ range with corresponding temperatures In the 50-to $10-\mathrm{eV}$ range, are predicted. (Somewhat lower plasma column densities might be observed in the actual experiment since $B$ can be expected to be less than unity.) For th1s range of plasma densities and temperatures, nonlinear absorption of the $\mathrm{CO}_{2}$ laser 11ght is 1ndicated. This bleaching frocess results in absorption lengths significantly greater than predicted for classical inverse bremsstrahlung absorption with constant absorption coefficlents. Such an effect should be easily observed in the Scylla I-C experiment.

The plasma response to laser energy absorption has been treated in a step-wise fashion, considering interparticle energy transfer mechanisms, heat conduction, and bulk motton of the heated plasma. The analyo1s Indicates that a laser Induced plasma column temperature Increase of about $10 \mathrm{eV}$ will be obtained after the transient energy transfer processes are completed and the heated plasma has reached a new equilibriun state. Th1s temperature increment is nearly independent of the initial $\theta-$ pinch fill pressure. Significantly higher cemperature Increases, on the order of $100 \mathrm{eV}$, can be expected during the time of the heating laser pulse ( $50 \mathrm{~ns}$ ).

Analysis of the power density thresholds for the laser light scattering instabllities shows that the Brillouin inatability threshold is exceeded over most of the Scylla I-C operating range. Accordingly, strong backscatter of the incident laser light could be expected, based on the calculated threshold levels. However, since the characteristic backscatter length scale 10BL is generally $\sim q a b$, the classical inverse bremsstrahlung absorption length, the observation of instablitty induced backscatter is uncertain.

The creation of an on-axis density minimum has been analyzed, assuming that local laser heating of the central core of irradiated plasma results in a local plasma expaneion that is rapid on the time scale of the laser pulse. Tite diffraction of the laser beat withtn this laser-induced density gradlent results in channeling of the incident laser light. Analysis of the laser light ray trajectories indicates that point-focusing of the channeling laser beam will occur, even in the presence of a very small, favorable density gradient $(\mathrm{dn} / \mathrm{dr}>0)$. Such beam focusing could result in local "hot spots" and beam illamentation, which would represent a serlous problem in attempting to uniformly heat the $100-\mathrm{cm}-$ long theta-pinch plasma column.

\section{REFERENCES}

1. A. Hertzberg, "Review of Controlled Fusion Research Using Laser HeatIng," AIAA Paper No. 73 258, January 1973.

2. L. C, Steinhauer and P. H. Rose, "Some Reactor Concepts Based on the Laser-Heated Solenold," MSNW Report No. 74-1903-1, April 1974.

3. N. A. Amherd and G. C. Vlases, " $\mathrm{CO}_{2}$ Laser Heat Ing of a Small O-PInch," Proc, of 2nd APS Topical Conf, on Pulsed High- $B$ Plasmas, Paper G4, July 1372.

4. R. Decoste et al., "Transverse Heating of a Cold Dense Helium Plasta by a Pulsed $\mathrm{CO}_{2}$ Laser Beam," J. Appl. Phys. 45, 1127 (1974). 
5. A. L. llof fman, "Strons Axial Laser Heating of a O-Pinch Plasina," Appl. Phys. l.ett. 23, 693 (1974).

6. C. M. Molen, " $\mathrm{CO}_{2}$ Laser Refraction and Heating Ef fects on a hagnetized Plasma Column," Tech. Report No. 3, Texas Tech. Univ., Dec. 1973.

7. J. F. Drake et al., "Parametrle Instabillties of Electromagnetic Waves in P2asmas," Phys. Fluids 17, 778 (1974).

8. W. R. Ellis and G. A. Sawyer, "Scaling Laws for the Linear Theta Pinch, I." LA-5434-MS, Oct. 1973.

9, G, T. Schappert, "Some Aspects of Heating with Laser Pulses," personal comunication.

10. K. Boyer et al., "Laser Heating of Magnet 1c Plasmas," personal communication.

11. W. H. Reichelt et al., "Gigawatt Pulses From a 3 Atmosphere $\mathrm{CO}_{2}$ Electron-Beam-Controlled Laser," personal coumuniration.

12. K. F. MeKenna, R. Kristal, K. S. Thomas, "Measurements of Plasma Density Distribution and Current-Sheath Structure on the Implosion Phase of a Theta-Pisch Discharge," Phys. Rev. Lett. 32, $410(1974)$.

13. F. L. Ribe, Ed., "Proposed Experiments on HeatIng, Staging, and Stabilization of Theta Pinches," LA-5026-P (R.evised), Feb. 1973.

14. J. Benford, "Rotation During the Impluston of a Theta Pinch," Plyss. Flusds 15, 435 (1972).

15. J. E. Hammel et al., "Implosion Heating Experiment," LA-5656-PR (1974).

16. K. F. McKenna et al., CTR-3 Quarterly Report, July-Sept. 1974.

17. L, Spitzer, Physics of Fully tonized Gases, 2nd Ed., Interscience Pub., New York (1962).

18. S. C. Burnett et al., "A Reference ThetaPinch Reactor (RTPR)," LA-5121-MS, Dec. 1972.

19. T. W. Johnston and J. M. Dawson, "Correct Values for High-Frequency Power Absorption by Inverse Bremsstrahlung in Plasmas," Phys. Fjulds 16, 722 (1973).

20. M. Kristiansen, Texas Tech, Univ., Lubbock, Texas, personal communication.

21. L. C. Stetnhauer and H. G. Ah1strom, "OneDimensional Laser Heating of a Stationary plasma," Phys. Fluids 14, 81 (1971).
22. L. C. Steinhauer and H. G. Ailstrom, "Bleaching Wave Phenomena," AIAA Journal I0, 429 (1972).

23. G. T. Schappert, "Sume Aspects of Laser Heating with Laser Pulses," personal comunication.

24. K. Buchl et al. In Laser Interaction and Related Plasma Phenomena, Plenum Press, New York, 1971, H. J. Schwarz and H. Hora, Eds.

25. E. Fabre and C. Stenz, "CO 2 Laser-Beam Absorption by a Dense Plasma," Phys. Rev. Lett. 32, 823 (1974).

26. D. W. Forslund, J. M. KIndeI, and E. L. Lindman, "Nonlinear Behavior of Stimulated Brillouin and Raman Scattering in Laser-Irradiated Plasmas," Phys. Rev. Lett. 30, 739 (1973).

27. C. S. Liu, M. N. Rosenbluth, and R. B. White, "Parameter Scattering Instabilities in Inhomogeneous Plasmas," Phys. Rev, Lett. 31, 697 (1973).

28. F. W. Perkins and E. J. Valeo, "Thermal SelfFocusing of EM Waves in Plasmas," Phys. Rev. Lett. 32, 1234 (1974).

29. J. M. Kinde1, "St Imulated Beckscatter in LaserHeated Pinches," Bu11 Am. Phys. Sor. 18, 1294 (1973).

30. D. W. Forslund, J. M. KindeI, and E. L. Lindman "The Theory of Stimulated Scattering Processes in Laser Irradiated Plasmas, I," submitted to Phys, of Fluids.

31. E. W. Forsiund, J. M. Kindel, and E. L. LIndman "Stimulated Scattering Processes in Laser Irradiated Plasmas, II," submtted to Phys. of Fluids.

32. B. D. Fried and F. W. Gould, "Longltudinal Ion Oscillations in a hot Plasta." Phys. Fluids 4. 139 (1961).

33 L. C. Steinhauer and H. G. Ahlstrom, "Propagagation of Coherent Radiation in a Cylindrical Plasma Column," Phys. Fluids 14, 1109 (171).

34. G. M. Molen M. Kristiansen, and M. O. Hagler, " $\mathrm{CO}_{2}$ Laser Beam Refraction in a Linear Discharge Plasma," Appl. Phys. Lett, 23, 601 (1973).

35. A. L, Hof $f$ man, Machemat ical Sclences Northwest, Inc., Seattle, Wash., personal communication.

36. I. P. Freidberg and H. Weitzner, "Endloss from a Linear O-Pinch," submitted to Nuclear Fusion. 